\title{
El retorno del populismo de derecha radical
}

Reseña de: Kahhat, Farid (2019). El eterno retorno. La derecha radical en el mundo contemporáneo. Lima: Editorial Planeta Perú.

Recibido: 30/08/2019

Aprobado: 17/09/2019
Aníbal Gauna, PhD. Universidad Nacional Mayor de San Marcos agauna@fulbrightmail.org

\section{Planteamiento de la cuestión}

El 20 de enero de 2017 el magnate Donald Trump se juramentaba como el $45^{\circ}$ presidente de los Estados Unidos, algo que apenas unos meses y quizá semanas (incluso días) antes hubiese sido prácticamente impensable para empresas encuestadoras y analistas políticos. Un hombre con su perfil (caracterizado regularmente por los medios y analistas como racista, misógino y narcisista, entre otros adjetivos de similar rango y naturaleza) no podía triunfar en el gran bastión de la democracia occidental. Pero ¿realmente no podía? Una mirada más atenta a Europa sugeriría lo contrario. Mencionemos solo un par de casos. En Francia, el conservador Front National de los Le Pen se hacía sentir con fuerza en sucesivas elecciones, llegando a obtener alrededor del 34\% de los votos en las presidenciales de 2017 (aunque el movimiento comienza en los 1970s). En Italia otro empresario outsider, Berlusconi, se lanzaba al ruedo político en 1994 y alcanzaba la presidencia. Posteriormente, Salvini ha logrado formar parte del gobierno, también sobre una plataforma nacionalista. En otro giro inesperado, tenemos el caso del llamado Brexit, el referéndum en el cual se votó a favor de la salida del Reino Unido de la Unión Europea en el 2016, resultado impulsado por el partido nacionalista UKIP (luego escindido con el Partido del Brexit). Estos ejemplos muy significativos no agotan el escenario: Holanda, Austria, Alemania, Polonia, Hungría, Rusia, Suiza, Australia, Bélgica, Grecia, han experimentado todos un resurgir de lo que Kahhat califica como "derecha populista radical" - por contraste con la "derecha tradicional" y a la que me referiré en adelante como DPR. En pocas 
palabras: la DPR ha conquistado en victorias electorales, los que antes se consideraban bastiones de la democracia liberal, o incluso de la socialdemocracia, en el mundo Occidental. ¿Por qué ha ocurrido esta reacción? ¿Cómo puede explicarse este fenómeno?

\section{Los argumentos}

El libro de Kahhat propone una constelación de respuestas a estas preguntas, a través de diez capítulos (más introducción y conclusiones) de prosa clara y directa. Pero antes de presentar la misma, es menester recordar la aclaratoria que el autor lleva a cabo: dichas respuestas no son resultado de sus propias investigaciones, son en realidad resultado de otros estudios (p.9, una afirmación muy modesta sobre la cual volveré al final) que Kahhat a veces sintetiza, a veces examina críticamente, pero siempre con lucidez e imparcialidad. Ante todo, Kahhat nos ofrece constantemente y desde el inicio del texto las preguntas apropiadas para poner en duda explicaciones de sentido común y encaminarnos hacia una propuesta de alcance general. Veamos algunos casos. La fecha que suele señalarse como clave en este fenómeno es diciembre de 2007, cuando comienza la crisis económica mundial. Pero el crecimiento electoral de la DPR se ha mantenido más de una década después de culminada la misma. Adicionalmente, el crecimiento de la DPR se constata en algunos países prácticamente no afectados por la misma (como Austria u Holanda), mientras en lugares severamente afectados no se constata (como Portugal) (p.187). ¿Puede entonces afirmarse que la crisis económica es la causa detrás del resurgir de la DPR, más aún cuando su discurso puede ser persuasivo también durante tiempos de bonanza económica (como en los casos de Australia y Holanda, pp.28-29)? Por otra parte, si el mismo es una respuesta al fenómeno de la inmigración, ¿por qué se desarrolla en lugares con nula inmigración (como Hungría) pero no en donde hay proporciones elevadas de población inmigrante (como Canadá)? (p.6).

Para empezar, puede afirmarse que las crisis económicas sí favorecen el crecimiento de la DPR, pero no son condición necesaria ni suficiente para explicarlo (p.185). El comercio internacional, particularmente resultado de las importaciones de China, y en general de países de bajos ingresos, ha reducido en el corto plazo los ingresos de los trabajadores de baja calificación en países desarrollados (p.54-57). Pero habría que añadir que es la 
falta de las políticas propias del Estado de bienestar, diseñadas para reducir el impacto de la transición de los trabajadores desde unos sectores de la economía hacia otros, y en general para proteger a los grupos más vulnerables frente a la competencia exterior (pp.57-58), lo que hace de la apertura comercial internacional un factor de malestar para los nuevos votantes de la DPR. En este sentido, más importante quizá sea la pérdida de trabajos industriales en países desarrollados debido a la automatización de procesos productivos (p.59). Lo que puede quedar oculto detrás de cifras bajas de desempleo es la proporción de la población que es considerada parte de la fuerza laboral, así como sus condiciones de remuneración y trabajo. De este modo se explicaría la coexistencia de bonanza económica con crecimiento electoral de la DPR.

Sin embargo, las variables culturales son mejores predictores del voto de la DPR que las variables económicas (p.29). Basado en el estudio de Norris e Inglehart (2018), quienes estudian doscientos sesenta y ocho partidos políticos de treinta y un países, principalmente países desarrollados (p.132), postula que lo que hay detrás de estos casos es un "cultural backlash", o "reacción cultural" (p.131, también p.97 y p.192); es decir, la reacción de los nativos a la percepción de que se estaría produciendo una pérdida de los valores tradicionales por la cual culpan principalmente a los inmigrantes. Por ello, el respaldo a la DPR es mayor entre quienes comparten valores tradicionales: adultos mayores, personas con menor nivel de educación formal, personas religiosas (p.133). Un dato relevante que viene a confirmar este argumento es que el carecer de título de educación superior fue un buen predictor tanto de que en el Reino Unido se votara a favor del Brexit como de que los blancos (no hispanos) votaran por Trump en los EEUU (p.48).

Mostrar el aspecto débil de las explicaciones del lado de la "demanda" conduce a Kahhat a destacar una de las cuestiones más cruciales del texto: la importancia de la construcción activa de marcos interpretativos en favor de la DPR por parte de sus liderazgos políticos, articulando una "oferta" electoral exitosa (p.19), actores que por otra parte politizaron los "males" vinculados con la inmigración antes que los conflictos distributivos (p.200). Sobre la base de la clásica noción sociológica de "profecía autocumplida", nos recuerda Kahhat que el discurso de la DPR tiene consecuencias reales, aunque no esté basado en evidencias sólidas sobre, entre otras cosas, la inmigración (pp.2021). Por ejemplo, estadísticamente, en Europa no hay mayor probabilidad de 
que los refugiados se involucren en el terrorismo o actividades criminales, de la que la hay para la población en general (p.65). Así mismo, el crimen en los EEUU se redujo precisamente durante los años en que la inmigración indocumentada creció, entre 1990 y principios de los 2000 (p.82). Por lo tanto, aparentemente es la sola presencia de los inmigrantes lo temido, pues se supone que conduce a una progresiva pérdida de la identidad cultural. Pero el discurso que vincula inmigración con criminalidad y malestar social puede ser eficaz para movilizar el respaldo en favor de la DPR (pp.79-80, p.89). Se añade a esto el hecho de que, según investigaciones en psicología social, cuando está en juego nuestras emociones e identidad y no solo nuestro raciocinio, la información verificada con base en fuentes contrastables puede no solo no ser suficiente, sino que incluso puede ser contraproducente (p.104). En tales situaciones, importa incluso más quién propone algo que aquello que propone (p.107). Los medios de comunicación son un actor relevante en este sentido. En el caso de los EEUU, los medios, incluso teniendo líneas editoriales críticas con Trump, le brindaron publicidad sin proponérselo, a cambio de la audiencia que obtenían por la cobertura de una campaña novedosa y sensacionalista (pp.116-117).

Por último, es importante mencionar los casos latinoamericanos. Mexico ha elegido un presidente de izquierda populista (López Obrdor) luego de cuatro gobiernos de derecha, mientras Brasil ha elegido un presidente de DPR (Bolsonaro), tras haber elegido cuatro gobiernos de izquierda (p.140). Lo primero que hay que decir es que en ninguno de los dos casos la inmigración y la "reacción cultural" a sus consecuencias son la explicación (nunca lo es para el populismo de izquierda). Tampoco lo determinante fue el factor ideológico: la elección de candidatos anti-establishment, tanto como las preferencias en políticas públicas de los electores, respondieron más a la búsqueda de soluciones a problemas prácticos y la insatisfacción frente al desempeño de gobiernos anteriores (p.145), y a una percepción negativa de la empresa privada (que no implica necesariamente una percepción positiva de la empresa pública) (p.144). Más aún, Bolsonaro en Brasil hizo su campaña sobre la base de una plataforma "Contra el globalismo" (como una buena parte de la DPR europea y Trump), pero ha dado un giro en favor de políticas de apertura de mercado, impulsado por razones prácticas: reducir la oposición de los gremios empresariales (p.158). Estas son diferencias notables respecto a la DPR en Europa y los EEUU. 


\section{Balance crítico}

El aspecto más obviamente faltante en el texto es que no se hace explícito el por qué se titula "El eterno retorno". En consecuencia, se echa de menos una discusión al menos breve de qué es en realidad lo que se puede considerar un "retorno" (y además "eterno") en el fenómeno actual. De hecho, puede disputarse si esta derecha que está triunfante en tantas partes del mundo es en realidad una derecha "radical", en comparación con el auténtico fascismo y nacionalsocialismo de la Europa de los 1930s y 1940s (se discute algo al respecto en la p.24, se menciona la excepción del Partido de la Libertad de Austria en la p.158 y se establecen paralelismos entre el discurso de Le Pen en Francia y las teorías conspirativas Nazis en las pp.181-182). Incluso hay autores que han creado índices para medir el nivel de fascismo de un régimen $\mathrm{y}$, aunque puede que compartan ciertos rasgos, no necesariamente los actuales PDR cumplen con el mínimo para ser calificados como tales, o no todos, ni quizá la mayoría (ver por ejemplo el artículo del profesor de historia de la Universidad de Georgetown, John McNeill, aparecido en The Washington Post el 21 de octubre de 2016, titulado: How fascist is Donald Trump?).

Por otra parte, el autor no solo deja en evidencia un amplio manejo de las fuentes, sino hace gala de un despliegue de herramientas analíticas y teóricas que sugieren que podría haber llevado a cabo un estudio comparativo propio sobre el tema, y sin embargo no encontrará el lector un análisis sistemático de ningún caso en particular (aunque tampoco era su objetivo, claro está). Dicha ausencia es decisiva pues la atribución de causalidad que se realiza en la obra puede resultar espuria. Por ejemplo, al dar cuenta de por qué puede haber bonanza económica con crecimiento de la DPR, se presenta una explicación basada en evidencia de los EEUU (el caso más referenciado a lo largo del libro) y no en los casos que cumplen ambas condiciones (Australia y Holanda). Así mismo, y por la misma razón, no responde una de las preguntas más agudas que él mismo ha formulado y que mencioné al inicio: si la explicación principal de este fenómeno se basa en la "reacción cultural", ¿por qué la DPR se desarrolla en lugares con nula inmigración (como Hungría) pero no en donde hay proporciones elevadas de población inmigrante (como Canadá)? La movilización de una agenda antinmigración por las elites políticas de la DPR no tendría sentido tampoco como respuesta en este contexto.

Finalmente, dado que el libro es de carácter general ("La derecha radical en el mundo contemporáneo"), uno podría esperar la inclusión de casos asiá- 
ticos, los cuales están virtualmente ausentes. Al menos Tailandia, Turquía y la India son casos pertinentes y podrían contribuir a la discusión sobre las causas del fenómeno. Esto, junto con la discusión de los casos latinoamericanos, proveería de una visión comparativa de las causas y consecuencias diferenciales a nivel global. Pero estos puntos podrían ser ya demasiado exigentes respecto a los objetivos que el autor se ha propuesto.

Considerando las importantes observaciones y reflexiones que se encuentran en el texto, el balance es en definitiva muy positivo. En esta reseña apenas me he referido a las ideas centrales respecto a qué explica el fenómeno de la DPR, pero me he visto obligado a omitir muchas otras cuestiones relevantes por razones de espacio. Y es que el libro está lleno de discusiones y referencias actuales y multidisciplinarias a una literatura que se encuentra en franco crecimiento a nivel internacional. En este sentido, es un trabajo de gran valía para tener un panorama amplio, actual y sin sesgos simplistas de la ola de partidos, líderes y movimientos de la DPR que está tomando buena parte del mundo por asalto. Más aún: es una valiosa referencia latinoamericana y peruana que nos aproxima a un fenómeno mundial cuyo alcance está aún por verse. 